\title{
Phytochemical Studies of Different Fractions of Galega officinalis Extract and Their Effects on Some Biochemical Parameters in Alloxan-Induced Diabetic Rats
}

\author{
C. D. Luka ${ }^{1^{*}}$, G. I. Adoga ${ }^{1}$ and G. Istifanus ${ }^{1}$ \\ ${ }^{1}$ Department of Biochemistry, Faculty of Medical Sciences, University of Jos, Jos, Nigeria.
}

Authors' contributions

This work was carried out in collaboration between all authors. Authors CDL and GIA designed the study and prepared the manuscript. Author GI managed the literature searches and prepared rat application. All authors read and approved the final manuscript.

Article Information

DOI: 10.9734/EJMP/2017/32145

Editor(s):

(1) Patrizia Diana, Department of Molecular and Biomolecular Sciences and Technologies, University of Palermo, Palermo,

(2) Marcello Iriti, Professor of Plant Biology and Pathology, Department of Agricultural and Environmental Sciences, Milan State

University, Italy.

Reviewers:

(1) Viduranga Waisundara, Rajarata University of Sri Lanka, Sri Lanka.

(2) Armando Zarrelli, University of Naples "Federico II", Italy.

(3) Lorna T. Enerva, Polytechnic University of the Philippines, Philippines.

Complete Peer review History: http://www.sciencedomain.org/review-history/19029

Original Research Article

Received $10^{\text {th }}$ February 2017 Accepted $4^{\text {th }}$ April 2017

Published $12^{\text {th }}$ May 2017

\begin{abstract}
Galega officinalis Linn (Goat's rue) is popularly called sakpani in Hausa speaking part of Nigeria. The Plant belongs to the family Leguminoseae. G. officinalis is chiefly used as an antidiabetic plant because of its ability to reduce blood sugar levels. The plant has positive effect on breast-milk production. Aqueous, methanolic, ethanolic and acetone extracts of the plant Galega officinalis Linn (Leguminoseae) and fractionations of the methanolic extracts were carried out in stages using standard procedures. Alkaloids, glycosides and flavonoids from the methanolic extracts of $G$. officinalis at $400 \mathrm{mg} / \mathrm{kg}$ body weight significantly $(p<0.05)$ reduced the plasma glucose concentration in diabetic treated rats at the $3^{\text {rd }}$ and $28^{\text {th }}$ day of treatment when compared to diabetic untreated rats with alkaloids, glycosides and flavonoids producing $81.61 \%, 27.20 \%$ and $21.76 \%$ decreases in glucose concentrations. Also alkaloids from the methanolic extracts of $G$. officinalis improved lipid profile and reverse the adverse effects of induced diabetic on selected marker
\end{abstract}


enzymes. Methanolic fractions $F_{1}, F_{2}, F_{3}$ and $F_{6}$ produced remarkable effect by decreasing glucose concentration in diabetic treated rats compared to diabetic untreated rats. Methanolic extract of $G$. officinalis proved to be a rich source of phytochemicals with potent hypoglycaemic and hypolipidemic effects.

Keywords: Galega officinalis; methanolic extracts; fractionation; diabetics; phytochemicals; hypoglycaemic potential.

\section{INTRODUCTION}

Plants as medicines have being practiced by man for the cure of several diseases for centuries $[1,2,3]$. At present, despite the abundance and advancement of synthetic drugs, a significant proportion of the population of developing countries still depend on traditional medicines for their health care needs [3]. According to World Health Organization 2001, $60 \%$ of the world's population depend on traditional medicine, and $80 \%$ of the population in developing countries depend almost entirely on traditional medical practices, in particular, herbal medicine for their primary health care needs [4,5]. In Traditional Chinese Medicine (TCM), for instance, the disease has been referred to as "Xiaokezheng" or "Xiaodanzheng," both of which mean diabetes [6]. In the Sri Lankan traditional medicinal system, the disease has been stated as "Madhumeha" [7]. Plants have always been an exemplary source of drugs and have directly or indirectly yielded many important medicines in the past. For instance, the discovery of the widely used hypoglycemic drug, Metformin, came from the traditional approach of using Galega officinalis [3]. Overall, herbal remedies are gaining popularity because of several advantages such as a comparatively lower incidence of side-effects at recommended dosages, better patient tolerance, relatively low cost, and acceptance due to a long history of use. From the perspective of diabetes, the more important cause is that herbal medicines provide rational means for remedying the disease condition as well as many other ailments which are obstinate and incurable in more Western systems of medicine. Medicinal plants continue to contribute significantly to modern prescription of drugs by providing lead compounds upon which the synthesis of new drugs are made. [2] reported that $60 \%$ of the anticancer drugs and $75 \%$ of the anti-infectious disease drugs approved from 1981-2002, could be traced to natural origins. In addition, $61 \%$ of all new chemical entities introduced worldwide as drugs during the same period could be traced to or were inspired by natural products [8].

Galega officinalis Linn (Goat's rue) is popularly called sakpani in Hausa speaking part of Nigeria. The Plant belongs to the family Leguminoseae. G. officinalis is chiefly used as an antidiabetic plant because of its ability to reduce blood sugar levels. The plant has positive effect on breastmilk production [9]. With over 800 herbal medicinal plants in use for the treatment of Diabetics [10], the search for active biomolecules from medicinal plants with anti-diabetic properties is still on.

\section{MATERIALS AND METHODS}

\subsection{Plant Material}

The plant G. officinalis Linn (Goat's rue, whole plant) was collected at Naraguta village, University of Jos permanent site, Plateau State, Nigeria. The plant was identified and authenticated at the Department of Plant Science and Technology, University of Jos, Nigeria. A Voucher sample was then deposited at the Federal College of Forestry, Jos, Plateau State with the voucher Number FHJ 101.

\subsection{Preparation of Extracts}

The plant material wasair dried under shade until constant weight was obtained and grinded to fine powdered form using a blender. $100 \mathrm{~g}$ of the powdered forms was weighed and dissolved in $1000 \mathrm{ml}$ of distilled water and boiled for 15 minutes, allowed to cool and then filtered using Whatman Filter paper Grade No. 1. The filtrate was then allowed to dry in a water bath $\left(50^{\circ} \mathrm{C}\right)$. The extract was stored in an air tight container and kept until required. The methanolic, ethanolic and acetone extracts were prepared using similar methods except that $100 \mathrm{~g}$ of the fine powder was dissolved in $400 \mathrm{ml}$ of the solvent respectively and allowed to stand for $3 \mathrm{~h}$. Filtrates were dried at room temperature as against water bath in aqueous extraction. 


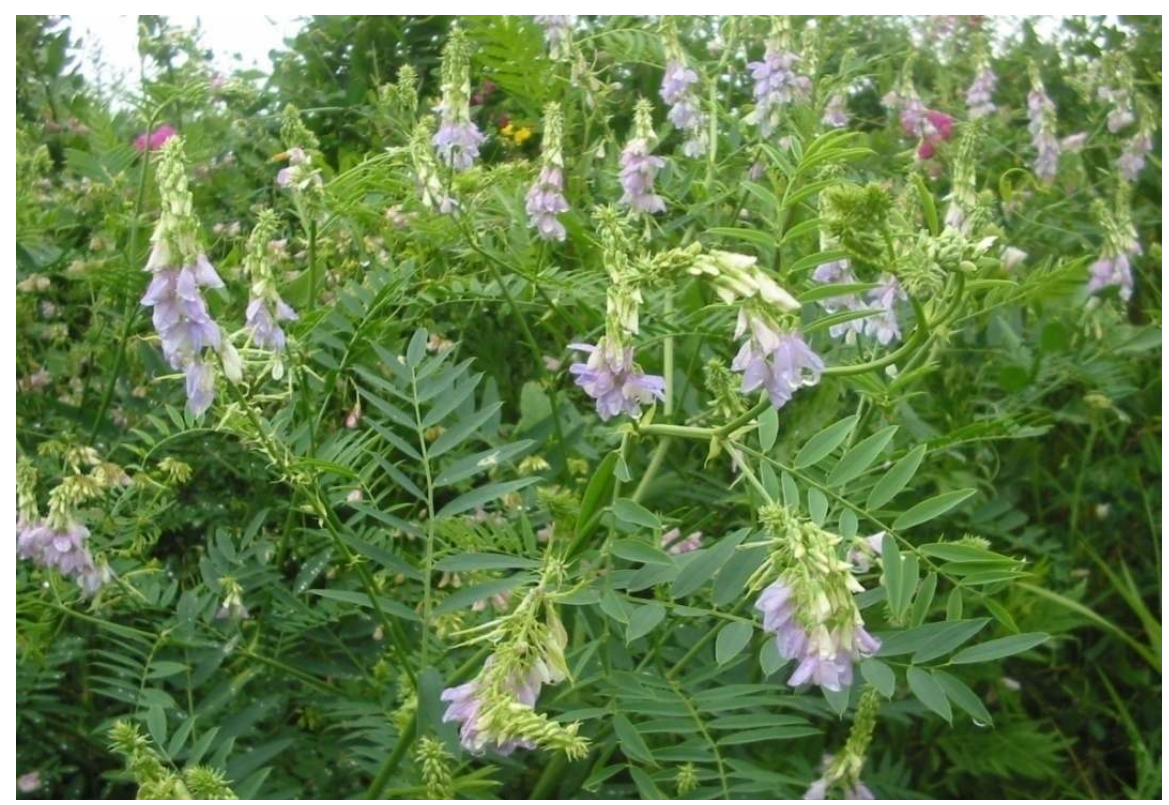

Fig. 1. Image of Galega officinalis Linn (Goat's rue) grown in Northern Nigeria

\subsection{Experimental Animals}

Male albino rats (Wistar Strain) weighing between 180-250 $\mathrm{g}$ used in this study were purchased from the animal house of the University of Jos, Nigeria and the National Veterinary Research Institute Vom, Nigeria. The animals were maintained under standard conditions, had free access to food (Grand Cereal, Oils and Mills Products, Jos, Nigeria) and water ad libitum. The animals were monitored with care and all the experimental procedure with the animals was in accordance with the internationally accepted principles for laboratory animal use and the experimental protocols were duly approved by the ethical committee of Animal House of Pharmacology Department University of Jos, Jos.

\subsection{Induction of Diabetics}

Diabetics mellitus was induced in animals by single intraperitonial injection of $150 \mathrm{mg} / \mathrm{kg}$ body weight of alloxan monohydrate (Sigma, St. Louis, USA) suspended in normal saline, after an overnight fasting. $48 \mathrm{~h}$ later diabetics were confirmed using One Touch Glucometre. Animal with fasting blood glucose level $\geq 250 \mathrm{mg} / \mathrm{dL}$ were considered diabetic and included in the study.

\subsection{Experimental Design}

The study was conducted in stages; Stage I: Phytochemical studies from different solvents,
Stage II: Diabetic studies of crude methanolic extract, Stage III: Phytochemical studies of crude methanolic extracts, Stage IV: Lipid profile studies of crude alkaloids from methanolic extract, Stage V: Fractionation of crude methanolic extract.

\section{Stage I:}

Crude extraction and phytochemical studies of different solvents extracts from G. officinalis Linn. using standard procedures. Phytochemicals screening was conducted using methods described by Harborne [11], Trease and Evans [12] and Sofowora [13]. Alkaloids, flavonoids, glycosides and saponins were also extracted from methanolic extracts of $G$. officinalis using standard procedures.

\section{Stage II:}

Twenty five albino rats were randomly assigned into five groups of five rats each and acclimatized for 7 days. Group A served as control and received $0.5 \mathrm{ml}$ distilled water, orally per day. Group B - E were diabetic induced rats administered $0.5 \mathrm{ml}$ distilled water, methanolic extract of $G$. officinalis, Garlic oil and Metformin (14.2 mg/kg bw), daily for 28 days respectively. Glucose concentrations were determined at the end of the study period. 


\section{Stage III:}

Thirty albino rats were randomly assigned into six groups of five rats each and acclimatized for 7 days. Group A served as control and received $0.5 \mathrm{ml}$ distilled water, orally per day. Group B - F were diabetic induced rats administered $0.5 \mathrm{ml}$ distilled water, alkaloids, flavonoids, glycosides and saponins from methanolic extract of $G$. officinalis respectively and glucose concentrations determined at $3^{\text {rd }}$ and $28^{\text {th }}$ day post treatment.

\section{Stage IV:}

Fifteen albino rats were randomly assigned into three groups of five rats each and acclimatized for 7 days. Group A served as control and received $0.5 \mathrm{ml}$ distilled water, orally per day. Group B and C were diabetic induced rats administered $0.5 \mathrm{ml}$ distilled water and alkaloids from methanolic extract of $G$. officinalis respectively. Animals were sacrificed at the $28^{\text {th }}$ day. Lipid profile and selected marker enzymes were assayed from prepared sera.

\section{Stage V:}

Fractions obtained from methanolic extracts of $G$. officinalis numbering seven $\left(F_{1}-F_{7}\right)$ were administered to experimental rats for 28 days, with plasma glucose determinations at $3^{\text {rd }}$ and $28^{\text {th }}$ day. The grouping was as follows: Forty five albino rats were randomly assigned into nine groups of five rats each and acclimatized for 7 days. Group A served as control and received $0.5 \mathrm{ml}$ distilled water, orally per day. Group Bwere diabetic induced rats administered $0.5 \mathrm{ml}$ distilled water per day while groups $\mathrm{C}$ - I were diabetic rats administer Fractions $F_{1}-F_{7}$ respectively.

\subsection{Collection of Samples}

At $3^{\text {rd }}$ and $28^{\text {th }}$ day of treatments, whole blood samples were collected from animals' tails. Using a One Touch ${ }^{\circledR}$ Glucometerkit, the blood glucose concentrations were determined. Prior to the $29^{\text {th }}$ day, the rats were subjected to an overnight fast. They were anesthetized at the time of sacrifice by been placed in a seal cotton wool soaked in diethyl ether inhalation jar. Blood samples were collected into centrifuge tubes and allowed to clot for about 45 minutes, after which they were spun at $5000 \mathrm{rpm}$ for 5 minutes, the serum collected were transferred into bijou bottle using pasture pipette and kept for analysis.

\subsection{Biochemical Parameters}

Biochemical parameters assayed; Total cholesterol concentration, serum HDLcholesterol and triacylglyceride were done using Randox diagnostic reagent kits. LDL-cholesterol was estimated using Friedewald formula [14]. Serum enzymes to include ALT and AST were determined by methods of Reitman and Frankel [15], while ALP was determined using KingArmstrong [16].

\subsection{Statistical Analysis}

Data were presented as Mean \pm Standard Deviation (SD) of 5 replicates and were analyzed using DMRT following one-way analysis of variance (ANOVA) using SPSS 16.0 computer software package (SPSS Inc., Chicago, U.S.A). Differences at $p<0.05$ were considered significant.

\section{RESULTS}

The phytochemicals screening of the raw $G$. officinalis Linn using selected solvents reveal that alkaloids, flavonoids, tannins, cardiac glycosides, terpenes and steroids were present in all four (Aqueous, Methanolic, Ethanolic and Acetone) extracts (Table 1). However, saponnis and resins were not detected in ethanolic and acetone extracts but present in aqueous and methanolic extracts of the plant while phenols and balsam were detected in only ethanolic and acetone extracts (Table 1).

Garlic oil administered to the diabetic rats showed a better result in lowering glucose levels in diabetic treated rats compared to metformin and methanolic extracts of $G$. officinalis Linn. However, all three treated groups had significantly $(p<0.05)$ decreased glucose levels when compared to diabetic untreated rats (Table 2).

Selected phytochemicals from methanolic extracts of $G$. officinalis Linn; alkaloids, flavonoids, glycosides and saponins administered at $400 \mathrm{mg} / \mathrm{kgbwt} /$ day for $28^{\text {th }}$ days, showed varying effects on glucose concentrations in diabetic rats. Alkaloids, flavonoids and glycosides expressed significant $(p<0.05)$ decrease in glucose concentrations at $3^{\text {rd }}$ Day $(28.98 \%, 35.94 \%, 18.84 \%)$ and $28^{\text {th }}$ Day $(81.61 \%, \quad 21.76 \%, \quad 27.20 \%)$ respectively. Saponins obtained from the plant could not 
express similar effect throughout the duration of the study (Table 3).

Total Cholesterol, TG, and LDL significantly $(p<0.05)$ decrease in diabetic rats treated with alkaloids from $G$. officinalis Linn. When compared to diabetic untreated rats with a corresponding significant $(p<0.05)$ increase in HDL of treated rats (Table 4).

The serum levels of marker enzymes (AST, ALT and ALP) in diabetic control (Untreated) rats increased significantly $(p<0.05)$ when compared to the normal control rats. Alkaloid extracts significantly reverse these changes in the marker enzymes when compared to diabetic untreated rats (Table 5).

Different fractions from methanolic extract of $G$. officinalis Linn were screened for phytochemicals and results presented in Table 6. Fraction $3\left(F_{3}\right)$ retained more of its phytochemicals with alkaloids, flavonoids, resins, terpenes and steroids present. This is closely followed by Fractions $2\left(F_{2}\right)$ while the least detected with a single phytochemical (cardiac glycosides) present is Fraction $1\left(F_{1}\right)$ (Table 6).

Various fractions from $G$. officinalis Linn methanolic extract showed varying effect on serum glucose levels in alloxan-induced diabetic rats (Table 7). At Day 3, all fractions had significant $(p<0.05)$ decrease in glucose level when compared to diabetic control. At Day 28, glucose levels were further reduced in diabetic treated rats especially fractions $1,2,3$ and 6 with $75.68 \%, 60.14 \%, 66.55 \%$ and $72.64 \%$ decrease in glucose concentration (Table 7).

Table 1. Phytochemical screening of G. officinalis Linn using selected solvents

\begin{tabular}{lllll}
\hline Phytochemicals & Aqueous & Methanol & Ethanol & Acetone \\
\hline Alkaloids & + & + & + & + \\
Flavonoids & + & + & + & + \\
Tannins & + & + & + & - \\
Saponins & + & + & - & + \\
Cardiac glycosides & + & + & + & + \\
Terpenes and steroids & + & + & - & + \\
Resins & + & + & + & + \\
Phenols & - & - & + & \\
Balsam & - & Key:+ = Detected; - = Not detected
\end{tabular}

Table 2. Weight variation in normal and diabetic rats

\begin{tabular}{lllll}
\hline Group & $\begin{array}{l}\text { Initial } \\
\text { weight }(\mathbf{g})\end{array}$ & $\begin{array}{l}\text { Final } \\
\text { weight } \mathbf{( g )}\end{array}$ & $\begin{array}{l}\text { Differential } \\
\text { weight } \mathbf{( g )}\end{array}$ & $\begin{array}{l}\text { Percentage } \\
\text { weight }(\%)\end{array}$ \\
\hline N C & 165 & 184 & +19 & +10.32 \\
D C & 175 & 154 & -22 & -14.28 \\
D + E & 160 & 164 & +4 & +2.44 \\
D + Std drug & 180 & 171 & +9 & +5.26 \\
\hline
\end{tabular}

Table 3. Effect of G. officinalis Linn methanolic extract, garlic oil and metformin on glucose level in alloxan-Induced diabetic rats

\begin{tabular}{lll}
\hline Group & Glucose concentration (mg/dl) & \% Decrease in Glucose Conc. \\
\hline Normal control & $77.4 \pm 1.2$ & NA \\
Diabetic control & $255.4 \pm 2.3^{\mathrm{b}}$ & NA \\
Diabetic + G. officinalis & $90.0 \pm 1.7^{\mathrm{c}}$ & 64.84 \\
Diabetic + Garlic oil & $81.0 \pm 1.2^{\mathrm{a}}$ & 68.29 \\
Diabetic + Metformin & $91.8 \pm 2.0^{\mathrm{c}}$ & 64.06 \\
\hline \multicolumn{2}{r}{ Values are mean \pm SD except for \% Decrease in Glucose Concentration, $n=5$} \\
\multicolumn{2}{r}{ a-c Values within a column with no common superscripts are significantly different $(p<0.05)$}
\end{tabular}


Table 4. Effect of some phytochemicals isolated from G. officinalis Linn methanolic extract on glucose level in alloxan-Induced diabetic rats

\begin{tabular}{lllll}
\hline \multirow{2}{*}{ Groups } & \multicolumn{2}{l}{ Glucose concentration $(\mathbf{m g} / \mathbf{d l})$} & \multicolumn{2}{l}{ \% Decrease in Glucose Conc. } \\
\cline { 2 - 5 } & $\mathbf{3}^{\text {rd }}$ day & $\mathbf{2 8}^{\text {th }}$ day & $\mathbf{3}^{\text {rd }}$ day & $\mathbf{2 8}^{\text {th }}$ day \\
\hline Normal control & $86.00 \pm 2.45^{\mathrm{a}}$ & $81.00 \pm 2.23^{\mathrm{a}}$ & $\mathrm{NA}$ & NA \\
Diabetic control & $345.00 \pm 4.12^{\mathrm{d}}$ & $386.00 \pm 2.56^{\mathrm{d}}$ & $\mathrm{NA}$ & NA \\
Diabetic + alkaloids & $245.00 \pm 1.44^{\mathrm{b}}$ & $71.00 \pm 2.55^{\mathrm{a}}$ & 28.98 & 81.61 \\
Diabetic + flavonoids & $221.00 \pm 2.55^{\mathrm{b}}$ & $302.00 \pm 1.58^{\mathrm{c}}$ & 35.94 & 21.76 \\
Diabetic + glycosides & $280.00 \pm 6.08^{\mathrm{c}}$ & $281.00 \pm 1.58^{\mathrm{b}}$ & 18.84 & 27.20 \\
Diabetic + saponins & $366.00 \pm 1.42^{\mathrm{e}}$ & $412.00 \pm 2.45^{\mathrm{e}}$ & -6.09 & -6.74 \\
\hline
\end{tabular}

Values are mean $\pm S D$ except for \% Decrease in Glucose Concentration, $n=5$

${ }^{a-e}$ Values within a column with no common superscripts are significantly different $(p<0.05)$

Table 5. Effect of alkaloid from G. officinalis Linn methanolic extract on lipid profile in alloxan-induced diabetic rats

\begin{tabular}{lllll}
\hline Groups & \multicolumn{4}{c}{ Lipid profile (Mmol/L) } \\
\cline { 2 - 5 } & Total Chol. & TG & HDL & LDL \\
\hline Normal control & $0.50 \pm 0.01^{\mathrm{a}}$ & $0.90 \pm 0.05^{\mathrm{a}}$ & $2.20 \pm 0.02^{\mathrm{a}}$ & $0.80 \pm 0.08^{\mathrm{a}}$ \\
Diabetic control & $2.40 \pm 0.08^{\mathrm{b}}$ & $2.70 \pm 0.08^{\mathrm{b}}$ & $0.67 \pm 0.05^{\mathrm{b}}$ & $2.94 \pm 0.01^{\mathrm{b}}$ \\
Diabetic + Alkaloid & $0.90 \pm 0.10^{\mathrm{c}}$ & $1.10 \pm 0.50^{\mathrm{a}}$ & $2.51 \pm 0.10^{\mathrm{c}}$ & $1.24 \pm 0.06^{\mathrm{c}}$ \\
\hline \multicolumn{5}{c}{ Values are Mean $\pm S . D, n=5$}
\end{tabular}

${ }^{a-c}$ Values within a column with no common superscripts are significantly different $(p<0.05)$

Table 6. Effect of alkaloid from G. officinalis Linn methanolic extract on some serum enzymes in alloxan-Induced diabetic rat

\begin{tabular}{llcc}
\hline Groups & \multicolumn{3}{c}{ Selected marker enzymes (Mmol/L) } \\
\cline { 2 - 4 } & AST & ALT & ALP \\
\hline Normal control & $274.33 \pm 1.10^{\mathrm{a}}$ & $103.33 \pm 1.10^{\mathrm{a}}$ & $208.00 \pm 0.82^{\mathrm{a}}$ \\
Diabetic control & $471.64 \pm 2.25^{\mathrm{b}}$ & $133.33 \pm 1.20^{\mathrm{b}}$ & $363.33 \pm 2.0^{\mathrm{b}}$ \\
Diabetic + Alkaloid & $277.50 \pm 2.01^{\mathrm{a}}$ & $106.20 \pm 1.10^{\mathrm{a}}$ & $210.10 \pm 1.50^{\mathrm{a}}$ \\
\hline \multicolumn{3}{r}{ Values are Mean $\pm S . D, n=5$} \\
\multicolumn{4}{c}{ a-c Values within a column with no common superscripts are significantly different $(p<0.05)$}
\end{tabular}

Table 7. Phytochemical screening of the fractions of G. officinalis Linn methanolic extracts

\begin{tabular}{llllllll}
\hline Phytochemicals & \multicolumn{7}{c}{ Fractions } \\
\cline { 2 - 8 } & $\mathbf{F}_{\mathbf{1}}$ & $\mathbf{F}_{\mathbf{2}}$ & $\mathbf{F}_{3}$ & $\mathbf{F}_{\mathbf{4}}$ & $\mathbf{F}_{5}$ & $\mathbf{F}_{6}$ & $\mathbf{F}_{\mathbf{7}}$ \\
\hline Alkaloids & - & + & + & - & - & - & - \\
Flavonoids & - & + & + & - & - & - & - \\
Tannins & - & - & - & - & + & + & + \\
Saponins & - & - & - & - & - & + & + \\
Cardiac glycosides & + & - & - & - & - & - & - \\
Terpenes and steroids & - & + & + & + & - & - & - \\
Resins & - & - & + & + & + & - & - \\
\hline
\end{tabular}

Key: + = Detected $-=$ Not detected

\section{DISCUSSION}

Diabetes Mellitus (DM) describes a metabolic disorder of multiple aetiology, it is characterized by chronic hyperglycaemia with disturbances of carbohydrate, fat and protein metabolism resulting from defects in insulin secretion, insulin action, or both. DM is a common endocrine disorder in which there occur increased food and water intake [17], it is a growing health concern worldwide [18]. The effects of diabetes mellitus include long-term damage, dysfunction and failure of various organs. Diabetes mellitus may present with characteristic symptoms such as thirst, polyuria, blurring of vision, and weight loss $[19,20]$. The present study wish to contribute to 
Table 8. Effect of different fractions of G. officinalis Linn methanolic extract on glucose level in alloxan-Induced diabetic rats

\begin{tabular}{|c|c|c|c|c|}
\hline \multirow[t]{2}{*}{ Fractions } & \multicolumn{2}{|c|}{ Glucose concentration (mg/dl) } & \multicolumn{2}{|c|}{$\%$ Decrease in glucose Conc } \\
\hline & $3^{\text {rd day }}$ & $28^{\text {th }}$ day & $3^{\text {rd }}$ day & $28^{\text {th }}$ day \\
\hline Normal control & $85 \pm 1.12^{\mathrm{a}}$ & $87 \pm 1.10^{\mathrm{a}}$ & NA & NA \\
\hline Diabetic control & $258 \pm 1.23^{\mathrm{b}}$ & $296 \pm 2.11^{d}$ & NA & NA \\
\hline Diabetic $+F_{1}$ & $175 \pm 1.35^{\mathrm{c}}$ & $72 \pm 1.10^{\mathrm{a}}$ & 32.17 & 75.68 \\
\hline Diabetic $+F_{2}$ & $198 \pm 1.32^{\mathrm{e}}$ & $118 \pm 1.21^{\mathrm{c}}$ & 23.26 & 60.14 \\
\hline Diabetic $+F_{3}$ & $197 \pm 1.33^{\mathrm{e}}$ & $99 \pm 1.22^{\mathrm{b}}$ & 23.64 & 66.55 \\
\hline Diabetic $+F_{4}$ & $168 \pm 1.10^{\mathrm{d}}$ & $216 \pm 2.41^{\mathrm{e}}$ & 34.88 & 27.03 \\
\hline Diabetic $+F_{5}$ & $148 \pm 1.22^{\mathrm{c}}$ & $119 \pm 1.33^{\mathrm{c}}$ & 42.63 & 32.77 \\
\hline Diabetic $+F_{6}$ & $151 \pm 1.12^{\mathrm{C}}$ & $81 \pm 1.22^{\mathrm{a}}$ & 41.47 & 72.64 \\
\hline Diabetic $+\mathrm{F}_{7}$ & $201 \pm 2.32^{\mathrm{e}}$ & $212 \pm 2.22^{\mathrm{e}}$ & 22.09 & 28.38 \\
\hline
\end{tabular}

the knowledge of $G$. officinalis in treatment of DM by a bio-guided fractionation of crude extracts of the plant.

The phytochemicals screening of the raw $G$. officinalis Linn using selected solvents reveals that alkaloids, flavonoids, tannins, cardiac glycosides, terpenes and steroids were present in all four (Aqueous, Methanolic, Ethanolic and Acetone) extracts (Table 1). Several phytochemicals including alkaloids, flavonoids, glycosides, glycolipid, steroids, carbohydrates, glycopeptides, terpenoids, amino acids, saponins and inorganic ions are known to affect various metabolic pathways, which in turn directly or indirectly affect the level of glucose in the human body $[21,22]$. G. officinalis prove to be rich in such phytochemicals which may produce potent hypoglycemic, anti-hyperglycemic and glucose suppressive activities.

Sharp difference was observed after induction of diabetes in the experimental rats as shown in Table 2. The normal control showed a significant increase in body weight whiles the diabetic control group, treatment groups showed a decrease in body weight.

Diabetic studies of crude methanolic extract of $G$. officinalis revealed the antidiabetic potentials of the plant. Methanolic extract from G. officinalis lowered the high blood glucose in diabetic rats in a similar manner with the reference drug metformin (Table 3). Garlic oil however, significantly expressed a better effect. A similar result of the effect of garlic oil on some biochemical parameters in diabetic induced rats has also been documented $[23,24]$. The above effects achieved by methanolic extract of $G$. officinalis is either by increasing serum levels of insulin or increasing the production of insulin from pancreatic $\beta$-cells, inhibit glucose absorption in the gut, stimulate glycogenesis in liver or increase glucose utilization by the body $[21,22,25]$. G. officinalis (Goat's rue) contains an alkaloid called Galegin which is key to its extraordinary anti diabetic effects. Galegin is chemically similar to Guanidine, the standard compound from which many conventional diabetic drugs are manufactured, such as metformin [26,27]. Ward, [28] also reported that the chemical benefits of $G$. officinalis on diabetic model are similar to that of metformin.

Alkaloids, flavonoids, glycosides and saponins were further extracts from methanolic extract of $G$ officinalis. Administration of these phytochemicals at a dosage of $400 \mathrm{mg} / \mathrm{kg}$ bwt./day for $28^{\text {th }}$ days, showed varying effects on glucose concentrations in diabetic rats (Table 4). Alkaloids, flavonoids and glycosides expressed significant $(p<0.05)$ decrease in plasma glucose concentrations at Day 3 and Day 28. Flavonoids present a $35.94 \%$ and $21.76 \%$ decrease respectively, expressing their natural hypoglycemic properties. It has been reported that some flavonoids possess hypoglycemic properties because they improve altered glucose and oxidative metabolism of the diabetic states [29]. However, at day 28, alkaloids produced $81.61 \%$ decrease in glucose concentration. These promising result increase our curiosity in investigating the effects of alkaloids from Methanolic extract of $G$. officinalis on lipid profile and selected marker enzymes in alloxan-induced diabetic rats (Table 5 and Table 6).

Alterations in serum lipid profile in diabetes are likely to increase the risk of coronary heart disease [30]. Significant $(p<0.05)$ reduction in 
serum lipids; total cholesterol, triglyceride and low density lipoprotein level in diabetic rats treated with alkaloids from methanolic extract of G. officinalis Linn should be considered as beneficial in long term prognosis of diabetes. Alterations in lipid metabolism; hypertriacylglycerolemia and hypercholesterolemia, as observed in diabetic untreated rats usually contribute to the pathogenesis of vascular complications in diabetes $[31,32]$. Alkaloids from methanolic extracts of $G$. officinalis Linn significantly $(p<0.05)$ reverse these alterations in lipid metabolism and also restore the protective role of HDL- cholesterol (Table 4).

The levels of AST, ALT and ALP were significantly $(p<0.05)$ increased in alloxaninduced diabetic untreated rats (Table 6) as previously reported [33,34]. Alkaloid extracts from $G$. officinalis Linn significantly reverse these changes in the marker enzymes when compared to diabetic untreated rats.

The last stage of this study involves the fractionation of methanolic extracts of $G$. officinalis Linn resulting in seven (7) fractions which were subjected to phytochemical screening and hypoglycaemic studies (Table 7 and Table 8). Fraction $3\left(F_{3}\right)$ retained more of its phytochemicals with alkaloids, flavonoids, resins, terpenes and steroids present and produced $66.55 \%$ decrease in glucose concentrations at day 28. These compounds (phytochemicals) may be responsible for the hypolipidemic effect and restoration of enzymatic functions [35] as supported by the data obtained. Alkaloids produced $81.61 \%$ reduction in glucose while crude methanolic extract produced $64.84 \%$ reduction in glucose when compared with diabetic untreated rats. Alkaloids from the methanolic extract could be responsible for the hypoglycemic properties of $G$. officinalis. None of the fractions could produce a greater effect as alkaloids from the methanolic extract at the $28^{\text {th }}$ day of treatment.

\section{CONCLUSION}

G. officinalis proved to be a rich source of phytochemicals and also revealed its antidiabetic potentials in experimental rats. Water, methanol, ethanol and acetone were able to extract a quit number of phytochemicals from the plant with the methanolic extract expressing a similar effect as metformin in diabetic treated rats. Furthermore, the methanolic extracts significantly improved the lipid profile and reverse adverse effect of diabetics on serum enzymes (AST, ALT and ALP). At day 28, fractions $F_{1}, F_{2}, F_{3}$ and $F_{6}$ obtained from the methanolic extract of $G$. officinalis produced remarkable effect by decreasing glucose concentration in diabetic treated rats.

\section{CONSENT}

It is not applicable.

\section{COMPETING INTERESTS}

Authors have declared that no competing interests exist.

\section{REFERENCES}

1. Philipeon JD. Phytochemistry and medicinal plants. Phytotherapy. 2001;56: 237-243.

2. Newman DJ, Cragg GM, Snader KM. Natural products as sources of new drugs over the period 1981-2002. Journal of Natural Products. 2003;66:1022-1032.

3. Lesney MS. Nature's pharmaceuticals: Natural products from plants remain at the core of modern medicinal chemistry. TCAW. 2004;13(7):26-31.

4. Fransworth NR. Ethnopharmacology and drug development. In Chadwick, D.J., and Marsh, J., (eds). Ethnobotany and the Search for New Drugs, CIBA Foundation Symposium 185, John Wiley and Sons, Chichester, New York. 1994;42-51.

5. Zhang BB, Moller DE. New approaches in the treatment of type 2 diabetes. Curr Opin Chem Biol. 2000;4:461-467.

6. Das SK, Chakrabarti R. Non-insulin dependent diabetes mellitus: Present therapies and new drug targets. MiniReviews in Medicinal Chemistry. 2005; 5(11):1019-1034.

7. Ediriweera ERHSS, Ratnasooriya WD. Review on herbs used in the treatment of diabetes mellitus by Sri Lankan ayurvedic and traditional physicians. AYU. 2009; 30(4):373-391.

8. Gupta R, Gabrielsen B, Ferguson FM. Nature's medicines: Traditional knowledge and intellectual property management. Case Studies from the National Institutes of Health $(\mathrm{NIH})$, USA Current Drug Discovery Technologies. 2005;2:203219. 
9. Chevallier A. The encyclopaedia of medicinal plants. London: Dorling Kindersley. 1996;33.

10. Preethi P. Jaya. Herbal medicine for diabetes mellitus: A Review. International Journal of Phytopharmacy. 2013;3(1):0122.

11. Harborne JB. Phytochemical methods. Chapman and Hall Ltd., London. 1973;49188.

12. Trease GE, WC. Evans, Pharmacognosy, $11^{\text {th }}$ edn., Bailliere Tindall, London. 1989;45-50.

13. Sofowora A. Medicinal plants and traditional medicine in Africa, Spectrum Books Ltd., Ibadan, Nigeria. 1993;289.

14. Warnick GR, Knopp RH, Fitzpatrick V, Branson L. Estimating low-density lipoprotein cholesterol by the Friedewald equaton is adequate for classifying patients on the basis of nationally recommended cutpoints. Clinical Chemistry. 1990;36(1):15-9.

15. Reitman S, Frankel S. A colorimetric method for the determination of serum glutamic oxaloaccetate and glutamic pyruvic transaminases. American Journal Ofclinical Pathology. 1957;28(1):56-63.

16. King EJ, Armstrong AR. Determination of serum and alkaline phosphatase activity. Canadian Medical Journal. 1964;31:376.

17. Pal GK, Pravatipal M, Mohan V. Srinivasan, Mohan M. Effect of catecholamines injected into nucleaus septal lateralis on feeding and drinking behavors in normal and streptozotocininduced diabetic rats. Biomedicine. 2001;21:46-55.

18. Ayesha Noor, Vinay S. Bansal, Vijayalakshmi MA. Current update on antidiabetic biomolecules from key traditional Indian medicinal plants. Current Science. 2013;104(6).

19. WHO. Definition, diagnosis and classification of diabetes mellitus and its complications, WHO Consultation Part 1: Diagnosis and Classification of Diabetes Mellitus, Geneva; 1999.

20. Cooke DW, Plotnick L. Type 1 diabetes mellitus in paediatrics. Pediatr Rev. 2008;29(11):374-84.

21. Grover JK, Vats V. Shifting paradigm from conventional to alternate medicine. An introduction on traditional Indian medicine. Asia Pac. Biotech News. 2001;5:28-32.
22. Saxena AM, Mukherjee SK, Shukla G. Progress of diabetes research in India during $20^{\text {th }}$ century. National Institute of Science and Communication (CSIR), New Delhi. 2006;1-104.

23. Adoga GI, Ibrahim BM. Effect of garlic oil on some biochemical parameters in streptozotocin induced diabetic rats. Medical Science Research. 1990;18:859860

24. Ohaeri OC. Effect of garlic oil on the levels of various enzymes in the serum and tissue of streptozotocin diabetic rats. Bioscience Reports. 2001;21(1):1924

25. Gupta R, Bajpai KG, Johri S, Saxena AM. An overview of Indian novel traditional medicinal plants with antidiabetic potentials. Afr. J. Tradit. Complement. Altern. Med. 2008;5:1-17.

26. Vuksan V, Sievenpiper JL. Herbal remedies in the management of diabetes: Lessons learned from the study of ginseng. Nutr. Metab. Cardiovasc. Dis. 2005;15(3): 149-160.

27. Hadden DR. Goat's rue - French lilac Italian fitch - Spanish sainfoin: Gallega officinalis and metformin: The Edinburgh connection. J R Coll Physicians Edinb. 2005;35(3):258-60.

28. Ward D. Vitamin Research News. $2001 ; 15(3): 4-5$.

29. Song Y, Manson JE, Buring JE, Howard D, Simin Liu S. Associations of dietary flavonoids with risk of type 2 diabetes and markers of insulin resistance and systemic inflammation in women: A prospective study and cross-sectional analysis. J. Am. Coll. Nutr. 2005;24:376-384.

30. Saikia H, Lama A. Effect of Bougainvillea spectabilis leaves on serum lipids in albino rats fed with high fat diet. International Journal of Pharmaceutical Sciences and Drug Research. $2011 ; 3(2): 141-145$.

31. Li WL, Zheng H, Bukuru CJ, De Kimpe N. Natural medicines used in the traditional Chinese medical system for therapy of diabetes mellitus. Journal of Ethnopharmacology. 2004;92(1):1-21.

32. Scoppola A, Montechi FR, Mezinger G, Lala A. Urinary mevalonate excretion of rats in type 2 diabetes: Role of metabolic control. Atherosclorosis 2001;156:357361. 
33. Gonzalez J, Fevery J. Spontaneously diabetic biobreeding rats and impairment of bile and independent bile flow and increased biliary bilirubin, calcium and lipid secretion. Hepatology. 1992;426-432.

34. Nwanjo HU. Studies on the effect of aqueous extract of Phyllanthus niruri on plasma glucose level and some hepatospecific markers in diabetic Wistar rats. Int. J. Lab. Med. 2007;2(2):1-18.

35. Mukherjee PK, Maiti K, Mukherjee K, Houghton PJ. Leads from Indian medicinal plants with hypoglycaemic potentials. J. Ethnopharmacol. 2006;106:1-28.

(C) 2017 Luka et al.; This is an Open Access article distributed under the terms of the Creative Commons Attribution License (http://creativecommons.org/licenses/by/4.0), which permits unrestricted use, distribution, and reproduction in any medium, provided the original work is properly cited.

Peer-review history:

The peer review history for this paper can be accessed here:

http://sciencedomain.org/review-history/19029 